Aksaray University
Journal of Science and Engineering
e-ISSN: 2587-1277
http://dergipark.gov.tr/asujse
http://asujse.aksaray.edu.tr

Research Article

\title{
Evaluating Spatial Legibility of the University Campus using GIS
}

\author{
Aslı Bozdağ ${ }^{1}$, M. Gizem Gümüşs, ${ }^{1, *}$ Kutalmış Gümüşs ${ }^{1}$, S. Savaş Durduran ${ }^{2}$ \\ ${ }^{1}$ Department of Geomatics Engineering, Faculty of Engineering, Nigde Omer Halisdemir University, Niğde, Turkey \\ ${ }^{2}$ Department of Geomatics Engineering, Faculty of Engineering, Necmettin Erbakan University, Konya, Turkey \\ -Received Date: Jul 09, 2020 \\ -Accepted Date: Nov 09, 2020 \\ -Published Online: Dec 26,2020
}

\begin{abstract}
Spatial legibility is related to the obtainment of spatial information (2D and 3D) that is in the urban area according to the characteristics of the observer who perceives this space. The aim of this research is to examine the spatial legibility of the campus of Selçuk University which is located in Konya province according to the characteristics of the area and the observer. The spatial characteristics of the application area were determined with the analyzes that were conducted with the help of Geographical Information Systems (GIS) and the characteristics of the observer were determined with analyzes that reveal the understanding of the observer to the area (Lynch analysis, questionnaire application and statistical evaluations). When the conducted spatial analyzes and statistical evaluations are examined, it was determined that the spatial legibility of the campus has a statistically significant relationship with the characteristics of the area and the observer.
\end{abstract}

\section{Keywords}

Spatial legibility, spatial awareness, environmental behavior, GIS.

\section{INTRODUCTION}

An urban environment is a formation which consists of physical, cultural and historical layers, includes many urban activities and is perceived by the people living in the city [1,2]. Perceiving the urban environment and the changes by the citizens takes place with the need for "understanding and discovering" [3]. Four informative variables are defined for understanding

*Corresponding Authour: M. Gizem Gumus, gizemkisaaga@ ohu.edu.tr, (D) 0000-0003-1361-3423 
and discovering the urban environment; mystery, complexity, legibility and coherence [4]. Among these variables, legibility is one of the principles of urban design and it increases the perception of the urban environment $[5,6]$.

There are various definitions of legibility. Overall, legibility reflects the possibility of coherence and organization of the objects that are designed in the urban environment in order for easy comprehension and recognition of an area, forming cognitive maps and easing the accessibility and direction finding [6-7]. The legibility of the urban area is related to the depiction of the city in the minds of people who are living in the city. The physical elements which are effective for the depiction of the city for the people living in the area were first defined by Lynch in 1960 [8]. Subsequently, Appleyard in 1969, Weisman in 1981 and Gärling, et al. in 1986 asserted theories on the determination of environmental elements that affect the spatial legibility [9-11]. Lastly, Köseoğlu defined two variables for the measurement of spatial dependencies of legibility in 2011. These are the information of spatial plan in the second dimension and the information of the area in the third dimension [12]. These variables are regarded to be more measurable than the concepts that are used in the literature for the definition of the legible environment such as simple, coherent, organizable, etc. [13]. However, the legibility of an area is shaped not only with these spatial variables but also with the effect of these variables on the emotions of the observer [14]. For this reason, spatial legibility is related to the process of obtaining information on spatial variables ( 2 dimensional and 3-dimensional spatial information) and the interpretation of the observer in the mind. In other words, the characteristics of the area and observer affect the process of obtaining information on the spatial variables in the provision of spatial legibility [12].

There are several studies that examine the characteristics of the area and observer in the process of obtaining spatial information. In these studies, spatial characteristics were examined in terms of circulation spaces in hospitals [15], metropolitan cities and University campus spaces $[16,17]$. and the characteristics of the observer were examined in terms of sight-disabled individuals [6], spatial perception change of young people [18] and people who experience the urban area for the first time (visitors) [14], Furthermore, the actions and experiences of individuals and associating the pieces of the city are important in the process of obtaining information on the spatial variables [15]. In this sense, there are several studies on obtaining spatial information in the $2^{\text {nd }}$ and $3^{\text {rd }}$ dimension and creating direction finding strategies $[13,19]$. The aim of this research is to examine the spatial legibility level of Selçuk University's (SU) campus area which is located in Konya province of Turkey. In the studies in the literature, the 
characteristics of the space and the observer were taken into consideration in the measurement of spatial legibility. In this research, different from the studies in the literature, the spatial legibility of the campus was examined on the plans that reflect the 2 nd and 3rd dimension of the campus along with the characteristics of the space and the observer. Spatial characteristics were reviewed with the macroform analysis of the campus, spatial-functional analysis and slope and visibility analyzes that were produced with the help of GIS as 2 and 3 dimensional. The characteristics of the observer were determined with the help of Lynch analysis which was conducted on the measurement of spatial perception of students who have and don't have spatial experience and with statistical evaluations on the results of the analysis. Finally, according to the obtained findings, it was examined whether or not the spatial legibility level of the campus space has a statistically significant relationship with the characteristics of the space and the observer.

With this research, it was aimed to contribute to the literature by revealing the necessity of comprehensively analyzing the characteristics of the observer and space in order to create legible urban areas which are successful, integrative and accessible in terms of the design of urban space.

\section{MATERIALS AND METHODS}

Perceiving a city with its open space structure and physical shape indicate that the city is simple and legible [20]. It is required for a city to be legible in terms of

- creating a memory map for the visitors to the city [20],

- carrying out the navigation easily by perceiving the environmental characteristics [21] and

- perceiving the third dimension of the space.

In the determination of changing legibility level, 2nd dimension (geometry) and 3rd dimension (landmarks) information are required [13, 22]. The information of the space in the 2 nd dimension is the geometry and its complexity. Geometry defines the second dimension of a space which facilitates and provides the navigation by revealing the spatial plan and the relationship of space with other spaces [12, 23, 24].

The information of the space in the 3rd dimension is the landmarks that are remarkable or affect the spatial legibility with its identifiability $[13,25,26]$. It is quite important for landmarks to be visible for successful navigation and perceiving the third dimension of the space [19]. The visibility information of the landmarks is used for traveling, comprehending or sharing the 
navigation instructions, translating the maps and organizing travel plans without any experiences in the environment [27].

In order to acquire this spatial information ( $2 \mathrm{nd}$ and $3 \mathrm{rd}$ dimension) from the environment easily and quickly, it should be simple, coherent, compatible with the environment, open and accommodable $[8,12,13,28]$. Spatial information that is obtained easily and quickly in the space increases the legibility of the space.

The way of obtaining the spatial information from the urban environment and the process of perceiving effect the characteristics of the space and the observer (physical and sociopsychological characteristics) $[12,29]$. In this context, the legibility of space is carried out by using the spatial information that was obtained according to the characteristics of the space and the observer from the environment (2-dimensional and 3-dimensional information) in a fit for purpose way by processing in the mind. The process that was stated in the Figure 1 also constitutes the fundamental structure of the research.

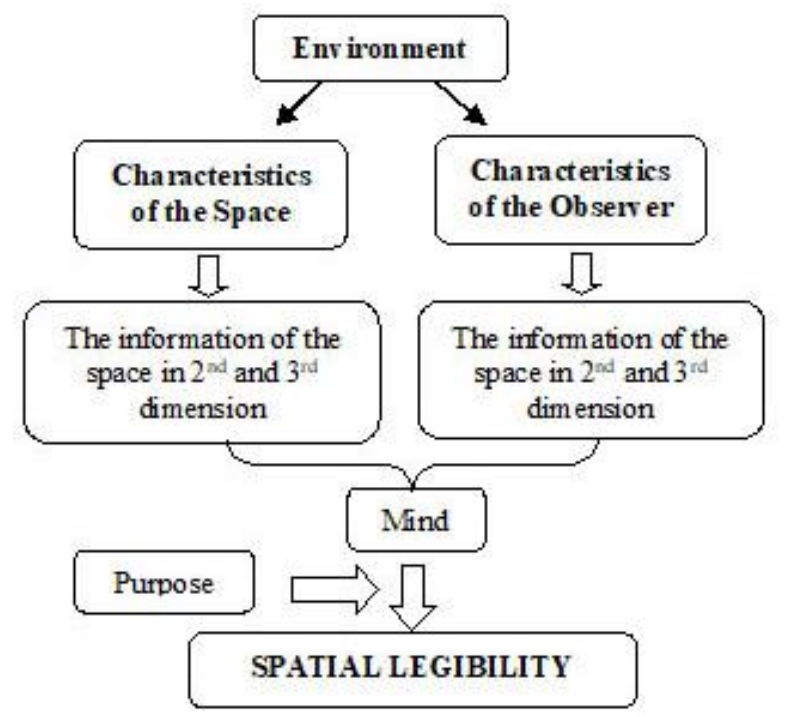

Figure 1. The Methodology of the study

The process of obtaining the $2^{\text {nd }}$ and $3^{\text {rd }}$ dimension information of the area in order to determine the spatial legibility level of Selçuk University which is located in the Konya province of Turkey that was chosen as application area was examined according to the characteristics of the space and the observer. The first stage of the research is related to the characteristics of the space and the second stage was related to the process of obtaining the spatial information (in $2^{\text {nd }}$ and $3^{\text {rd }}$ dimension) according to the characteristics of the observer.

The characteristics of the space are defined as the natural and artificial environment, historic dimension and cultural dimension. The characteristics of the observer are defined as the physical and socio-psychological characteristics of the individual [14]. 
In the first stage, the legibility of S.U. campus space which was determined as application area was examined in terms of spatial characteristics. Accordingly, the maps which reveal the spatial information of the campus that was determined as

- application area was produced with the help of GIS in $2^{\text {nd }}$ dimension (macroform development of the campus and function analysis) and

- in the $3^{\text {rd }}$ dimension (slope analysis and visibility analysis). Spatial legibility of the campus was examined on these maps which reflect the characteristics of the area.

- In the second stage, the legibility level of SU campus area was examined in terms of the characteristics of the observer with the help of Lynch analysis. Kevin Lynch determined five legibility elements in 1960 which define the characteristics of the space depending on the understanding of the individuals and their perception of the area. These are; paths, edges, districts, nodes, and landmarks [18, 26, 30-32].

- The sample group which had spatial experience was chosen from the students of Engineering Faculty in Geomatic Engineering at (SU) and the sample group which didn't have spatial experience was chosen from the students of Geomatic Engineering at Necmettin Erbakan University (NEU). The number of students who had spatial experience is 30 and the number of students who didn't have spatial experience was 35 . In the content of the questionnaire, it was required from students to score the Lynch elements on fivepoint Likert scale (least:1, low:2, medium:3, high:4 and most:5). (Figure2).

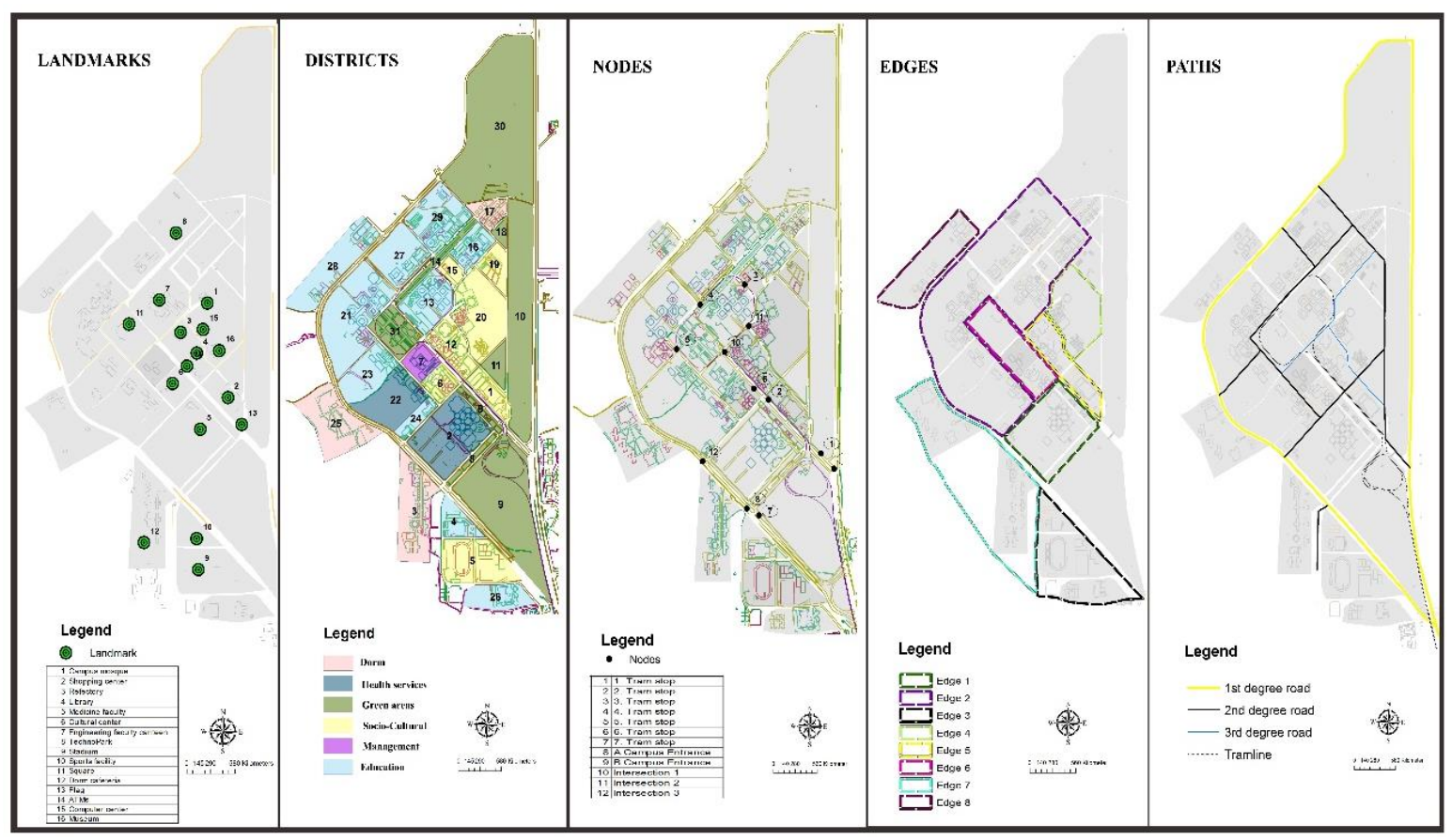

Figure 2. The Lynch elements of Campus 
According to the average scores which were obtained from the scoring, each Lynch element was mapped separately in terms of students who have spatial experience (SU) and don't have (NEU) with the help of ArcGIS 10.6 software. It was statistically analyzed whether or not there were significant differences between the students who have spatial experience (SU) and don't have (NEU) related to each Lynch element. T-test was used as a statistical analysis method since there were two sample groups. The t-test is used in order to examine whether or not there is a statistically significant relationship between the two sample groups in terms of averages. In scientific studies, T-test is preferred in cases when the number of sample group is few, the standard deviation of the main population is unknown and the parameters of the main population is not used in hypothesis test. According to the independent sample t-test results which were conducted for each Lynch element, the statistical results that were obtained on the questionnaire answers of students who have and don't have spatial experience were given in tables and it was interpreted whether or not there were any significant differences.

As a result of the research, spatial legibility of the campus was examined based on the characteristics of the space and the observer. It was determined that there was a significant relationship between the spatial legibility of the campus and the characteristics of the observer and space.

\section{EXAMINING THE SPATIAL LEGIBILITY OF SELÇUK UNIVERSITY'S (S.U.) CAMPUS}

\subsection{Examining the Application Area according to the Spatial Characteristics}

In the determination of application area according to the spatial characteristics, maps were produced on the macroform analysis, present condition analysis (natural and artificial environment), and slope and visibility analysis by benefiting from GIS.

\section{S. U. Campus Area Macroform Analysis}

S. U. Campus area was established in 1975 in Konya province which has the largest acreage in Turkey (Figure 3). According to the statistics of 2016-2017, there were a total of 73045 students as 58488 students in undergraduate and associate degree program and 14557 postgraduate students in S.U. campus which is located in Konya province of Turkey. Furthermore, it has the third largest campus area in Turkey.

The campus area is located in the northern entrance of the city, adjacent to the Afyon highway on an integrative terrain (Figure 3). The location of the campus is an important urban image at 
the entrance of the city. This situation provides spatial legibility which would leave a mark in the mind of first-time visitors.

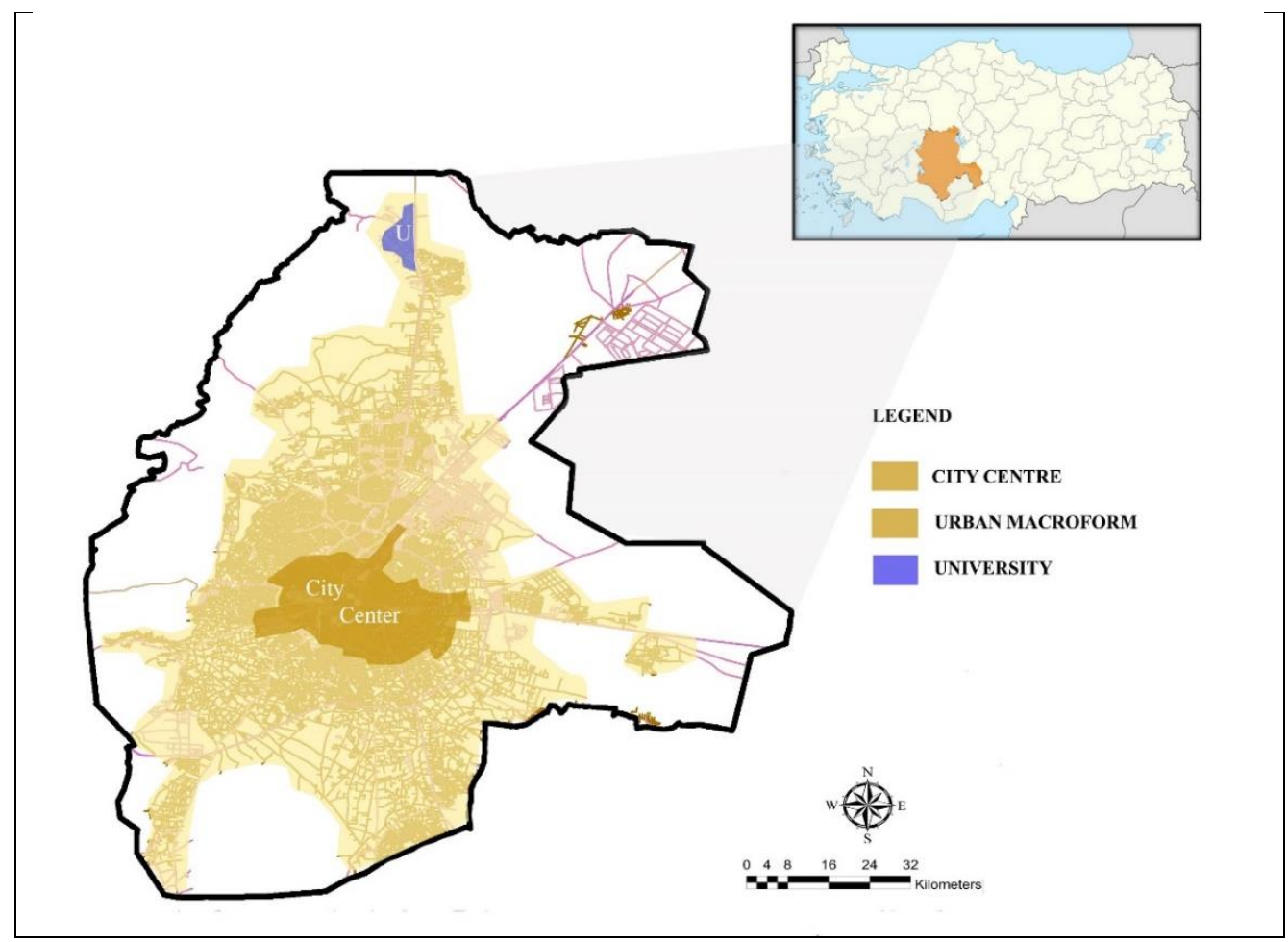

Figure 3. General view of the study area

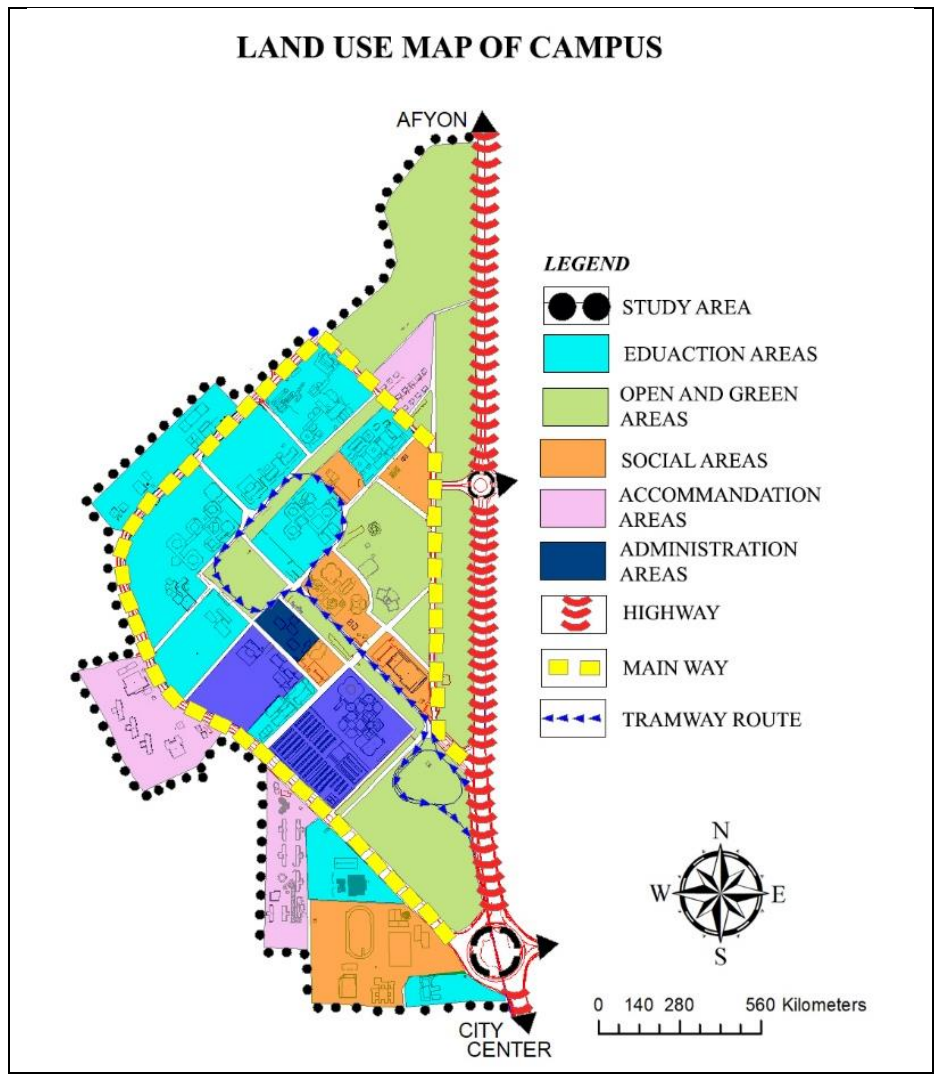

Figure 4. The land use plan of Campus 


\section{S. U. Campus Land Use Analysis (natural and artificial environment)}

Land use analysis defines the geometry of the space in the $2^{\text {nd }}$ dimension and its complexity. Land use analysis is required for obtaining the spatial information of the campus in $2^{\text {nd }}$ dimension which reflects the focus points in the space, functional clustering and interspatial transitions and connections. The Land Use Analysis (natural and artificial environment) of S.U. Campus Area was presented in the Figure 4.

There are functional uses in the campus area which would correspond to the needs of the livings in terms of planning and design. The campus is located on the highway that leads to the city center of Konya. This situation provides students from other cities to perceive the location of the campus area in the city in an integrated way. When the functional distribution in the campus area is examined, educational areas, green areas, social areas, accommodation areas and administration areas are clustered in certain regions. This clustering prevents spatial complexity. Recreational focus points were created by integrating the social areas and green areas. Accommodation areas provided focus points which would be near the borders of campus area and to the highways. Health areas are located on the main road and trolley line in the campus area and integrated with social facilities. The location of the health areas increases the accessibility to the health service by the people who live and don't live on the campus. Trolley line which forms a ring in the campus by starting from the city center increases to establish connections between different functions in the campus since it provides public transportation in the campus. This situation increases the spatial legibility while navigating and the accessibility in the campus.

\section{S. U. Campus Area Visibility Analysis}

The information of the space in the $3^{\text {rd }}$ dimension is the landmarks and other architectural structures which affect the spatial legibility with its identifiability and are remarkable in the $3^{\text {rd }}$ dimension. In this research, visibility analysis was used for obtaining the information of the space in the $3^{\text {rd }}$ dimension. Visibility analysis provides the analysis of visible and subvisible areas in the study area from one or more pre-determined observation points $[33,34]$. In this analysis, it is required from observation points to be higher than its surroundings in terms of observing and perceiving more spaces. Furthermore, visibility analysis results differ according to the morphological condition of the area, in other words, ruggedness, plainness, etc. Overall, the observed areas are less in sloping and rugged terrains. 
The areas which affect the spatial perception were determined with the visibility analysis that was carried out in the campus in the $3^{\text {rd }}$ dimension. For this, 3 frequently used trolley stops were determined as observation points. From these observation points, visibility analysis was carried out in GIS environment for education and service structures on the campus (Figure 5).

The determined observation points are respectively; V1: Central Trolley Stop, V2: Shopping Center, V3: In front of the Faculty of Engineering. The visible areas were shown with green color and subvisible areas were shown with red color in the analysis which was created from these 3 different observation points. For a person who enters the campus for the first time from the V1 observation point, the first perceivable landmarks are the Faculty of Medicine and graduate schools and then the rectorate building. For the person who observes the campus from the V2 observation point, Faculty of Medicine, Rectorate and graduate schools can be observed. From the V3 observation point, the results are the same. According to the visibility analysis results from these observation points, it can be stated that the high-rise architectural structures which can be easily seen from the surroundings of the campus are perceived more spatially.

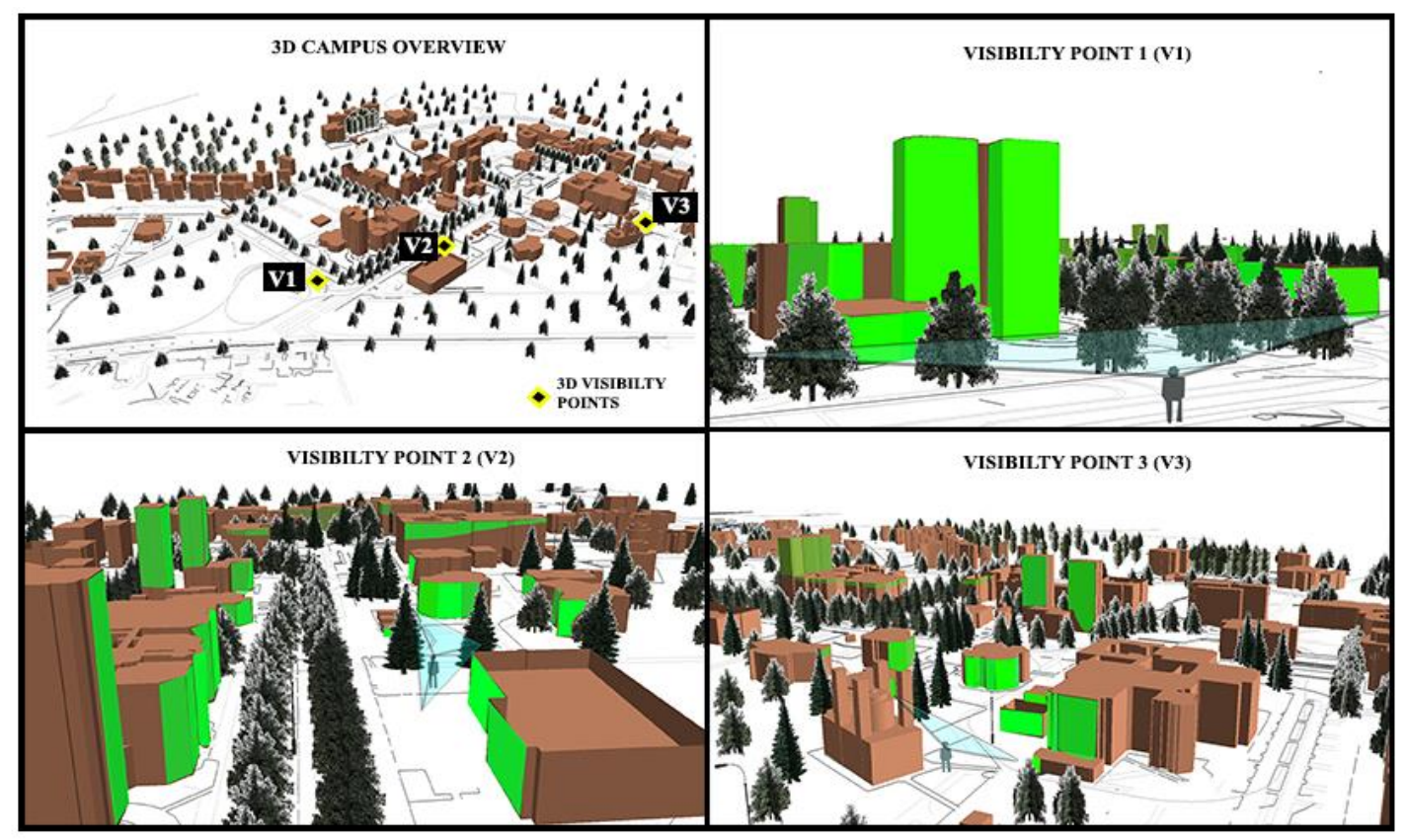

Figure 5. Visibility analysis of campus determined from the specific points

When the analysis and maps on the spatial characteristics of the campus are examined, it can be stated that the spatial information of the campus in $2^{\text {nd }}$ and $3^{\text {rd }}$ dimension can be easily obtained and can be used fit for purpose. For this reason, the campus is spatially legible.

\section{Examining the Application Area according to the Characteristics of the Observer}

The legibility level of S.U. campus area was examined in terms of the characteristics of the observer. The perceptibility and image of space differs according to the physical and socio- 
psychological characteristics of an observer [35, 36]. physical characteristics of individuals are defined as their height, weight, features of their eyes, their age, gender and characteristics of their sense and their socio-psychological characteristics are defined as their expectations, learning processes, lifestyle, income, cultural and ethnic background, social class, spatial experiences, memory and needs $[14,18,29]$.

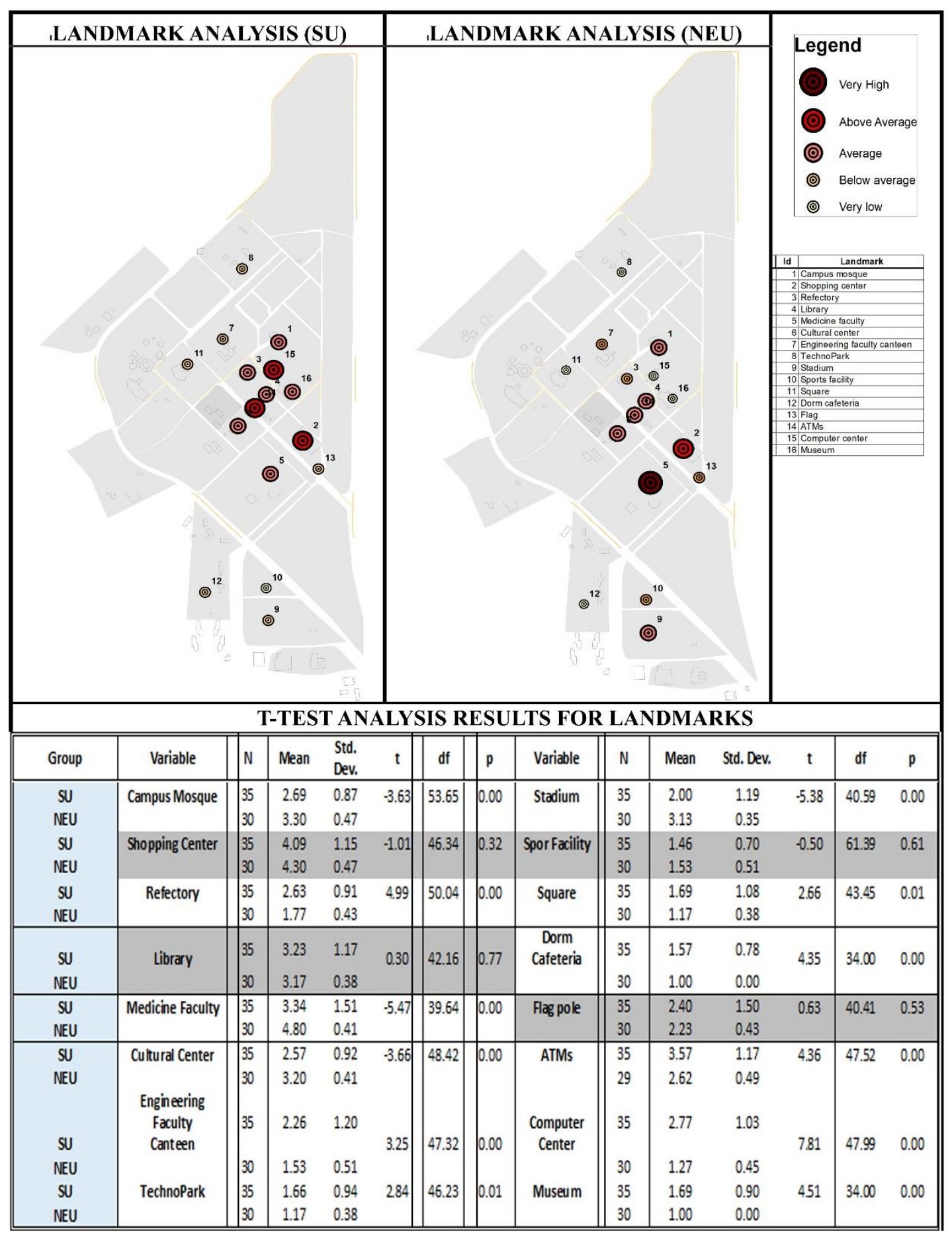

Figure 6. The results of Lynch analysis and $\mathrm{T}$ test analysis on landmarks 
The visual and spatial experience of individuals can change the spatial reference framework [37]. This changes the level of spatial legibility level. In this research, the spatial experience among the socio-psychological characteristics of an individual was accepted as the variable. The legibility level of the campus (in $2^{\text {nd }}$ and $3^{\text {rd }}$ dimension) was examined according to the meaning that groups give to space as the group that has spatial experience (SU) and the group that doesn't have spatial experience (NEU).

It was required from students who have spatial experience in the campus area (SU) and don't have (NEU) to score the Lynch compounds that they perceive while navigating in five-point Likert scale (least:1, low:2, medium:3, high:4 and most:5). According to the average scores that were obtained from the scoring, the Lynch compounds were visualized on a map with GIS in terms of the students who have spatial experience (SU) and don't have (NEU). Furthermore, whether or not there is a statistically significant difference between the answers that were given by these two groups on the Lynch analysis compound was analyzed with independent sample T-test.

When the T-test results were examined, it was observed that there was a significant difference between the averages of two groups on each Lynch compound. In the results of the analysis, $\mathrm{P}$ (Sig ( 2 tailed) result $(\mathrm{p}=0.000)$ also expresses that there is a statistically significant difference between the averages of the groups. $\mathrm{P}$ value (sig.) in $95 \%$ confidence interval defines a statistically significant difference in cases where it is lower than 0.05 and defines that there is not a statistically significant difference in cases where it is higher than 0.05 .

In the results of the analysis, the interpretation of Levene's Test for Equality of Variances part was conducted according to the Equal variances not assumed. Since there were differences between these group distributions, unequal variance assumption was used. However, in the analysis that is performed according to the different variables between these two groups, the important value is $\mathrm{p}(\mathrm{sig}(2$ tailed $))$. In this application, since the $\mathrm{p}$-value is $(\mathrm{p}=0.000)$ zero whichever variance dispersion we use, there wouldn't be any difference in the analysis interpretations.

Below,

- maps that were produced with GIS and

- independent sample T-test analysis results

were interpreted according to the questionnaire results which were conducted on each Lynch compound that both groups perceived while navigating in the campus area by giving them in tables. 
When the map and analysis results on landmarks were examined, in all of the landmarks except for shopping center, library, sports facilities and the flag pole, a statistically significant difference was determined between the averages of these two groups depending on the different variables on $\mathrm{p}<0.05$ significance level and in $95 \%$ confidence interval (Figure 6). Accordingly, shopping center, library, flag pole and sports facilities are common landmarks that both groups perceived while navigating in the space. Since shopping center is shopping-focused, the library is aimed at educational activities and sports facility is the space which is used for sports activities and annual festivals, they were involved in the spatial perception borders of both groups. For other determined landmarks, the landmarks that both groups perceive while navigating differ. While cafeteria, dorm cafeteria, ATM and Computer Center come into prominence in terms of the benefited landmarks while navigating for SU students who have the spatial experience, Faculty of Medicine comes into prominence in terms of the most benefited landmark while navigating for NEU students who don't have spatial experience. It was determined that SU students perceived the spaces of which they use frequently and provide their needs on food, shopping and educational activities as landmarks and NEU students perceived the Faculty of Medicine as a landmark since they receive medical service.

When the map and analysis results were examined according to the districts, in all of the districts except for District 9, District 18, District 19 and District 30, a statistically significant difference was determined between the averages of these two groups depending on the different variables on $\mathrm{p}<0.05$ significance level and in $95 \%$ confidence interval (Figure 7 ). Accordingly, both groups which have (SU) and don't have (NEU) spatial experience perceive these districts (District 9, District 18, District 19 and District 30) similarly. Districts of 18, 19 and 30 are the reserve area districts that are defined as green areas in the campus. District 9 is the trolley stop which represents the entrance to the campus borders. For this reason, both of the student groups perceived this district similarly.

When the averages of both groups were compared in other districts, it was determined that the averages of SU students who have spatial experience were higher than NEU student who don't have spatial experience. According to this, SU students perceive more districts while navigating than NEU students. It was determined that SU students who have spatial experience benefit the most from District 13 which is their faculties, District 12 which is the cafeteria, District 20 which is the Computer Center. 


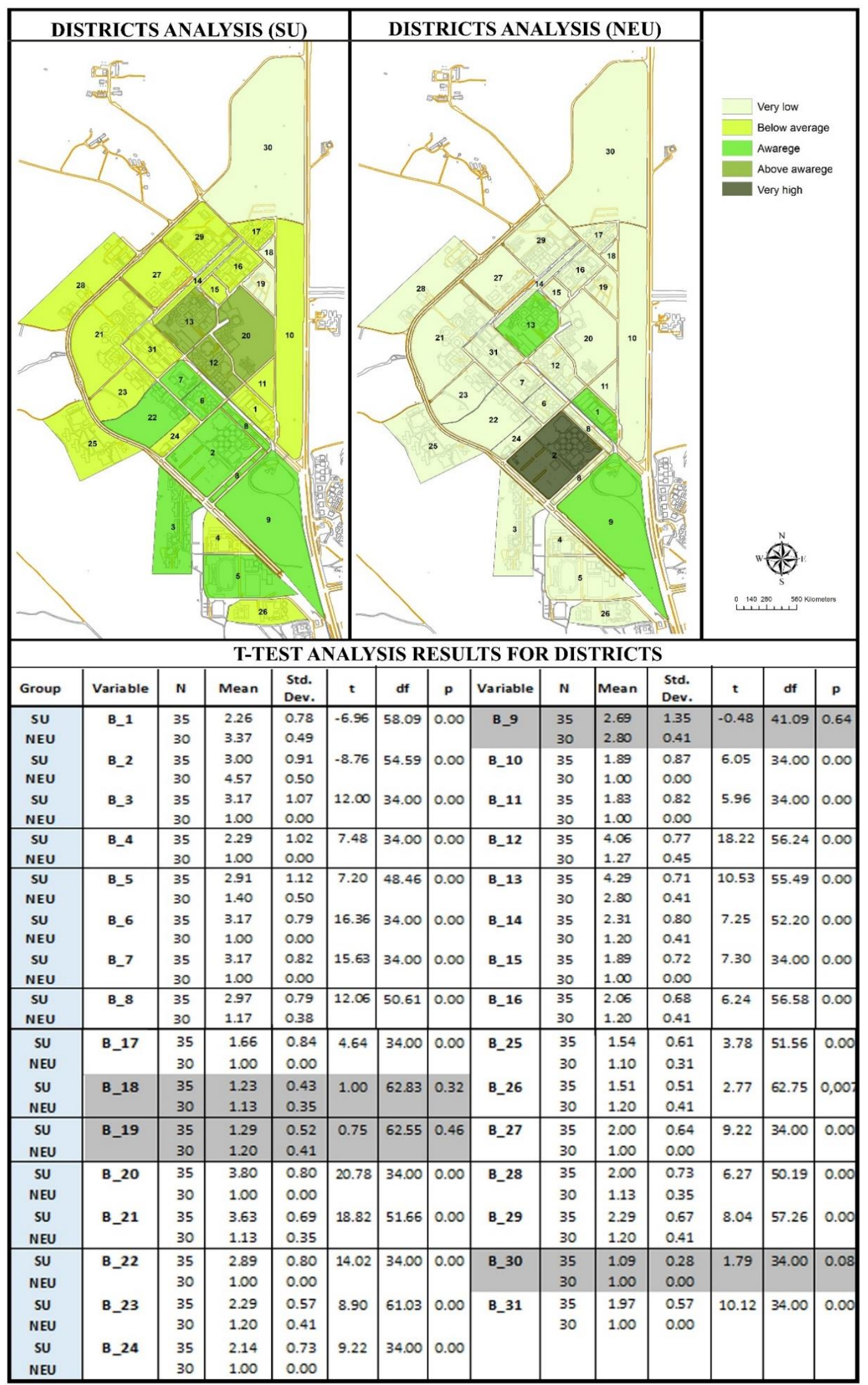

Figure 7. The results of Lynch analysis and $\mathrm{T}$ test analysis on districts 


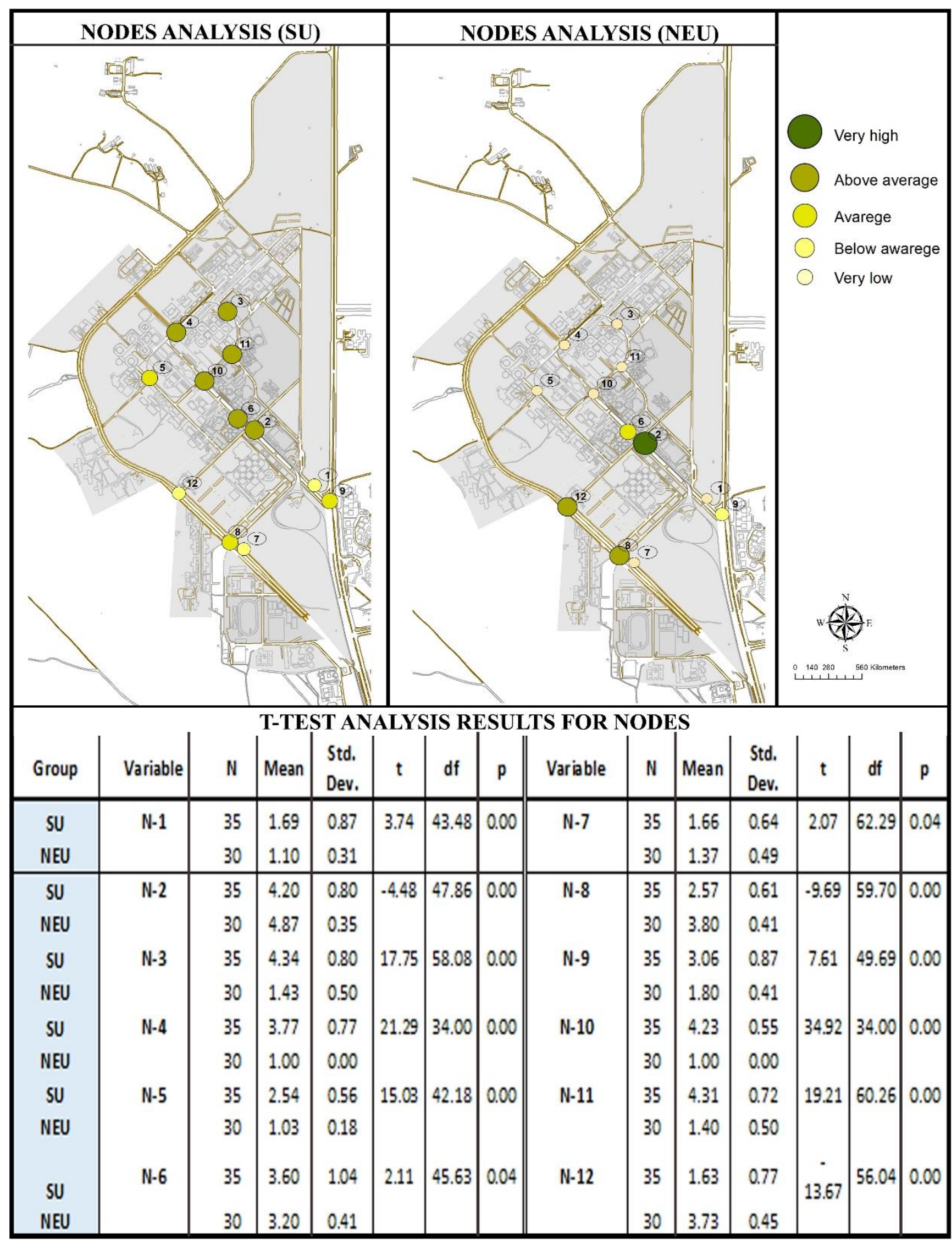

Figure 8. The results of Lynch analysis and $\mathrm{T}$ test analysis on nodes

It was also determined that NEU students who don't have spatial experience benefit the most from District 2 which is the faculty of medicine, District 1 which is the shopping center and District 13 which is the Faculty of Engineering. In addition to being higher than other buildings, the faculty of medicine is perceived higher by the NEU students since it provides health service. Since NEU students are studying in Geomatic engineering and already knew the Faculty of Engineering in the SU campus, they could perceive the District 13 better than other districts. 
When the map and analysis results on the nodes were examined, a statistically significant difference was determined between the averages of these two groups depending on the different variables on $p<0.05$ significance level and in $95 \%$ confidence interval (Figure 8). Accordingly, both of the groups don't perceive the node points similarly while navigating. The reason for this is that SU students perceive almost each node point on an average level while navigating. This situation may derive from the fact that SU students use these node points regularly. The spatial perception may differ subjectively according to the transportation points of the car, pedestrian and trolley. It can be observed that NEU students perceive the campus entrance and the stops in the points that reach to the Faculty of Medicine while navigating.

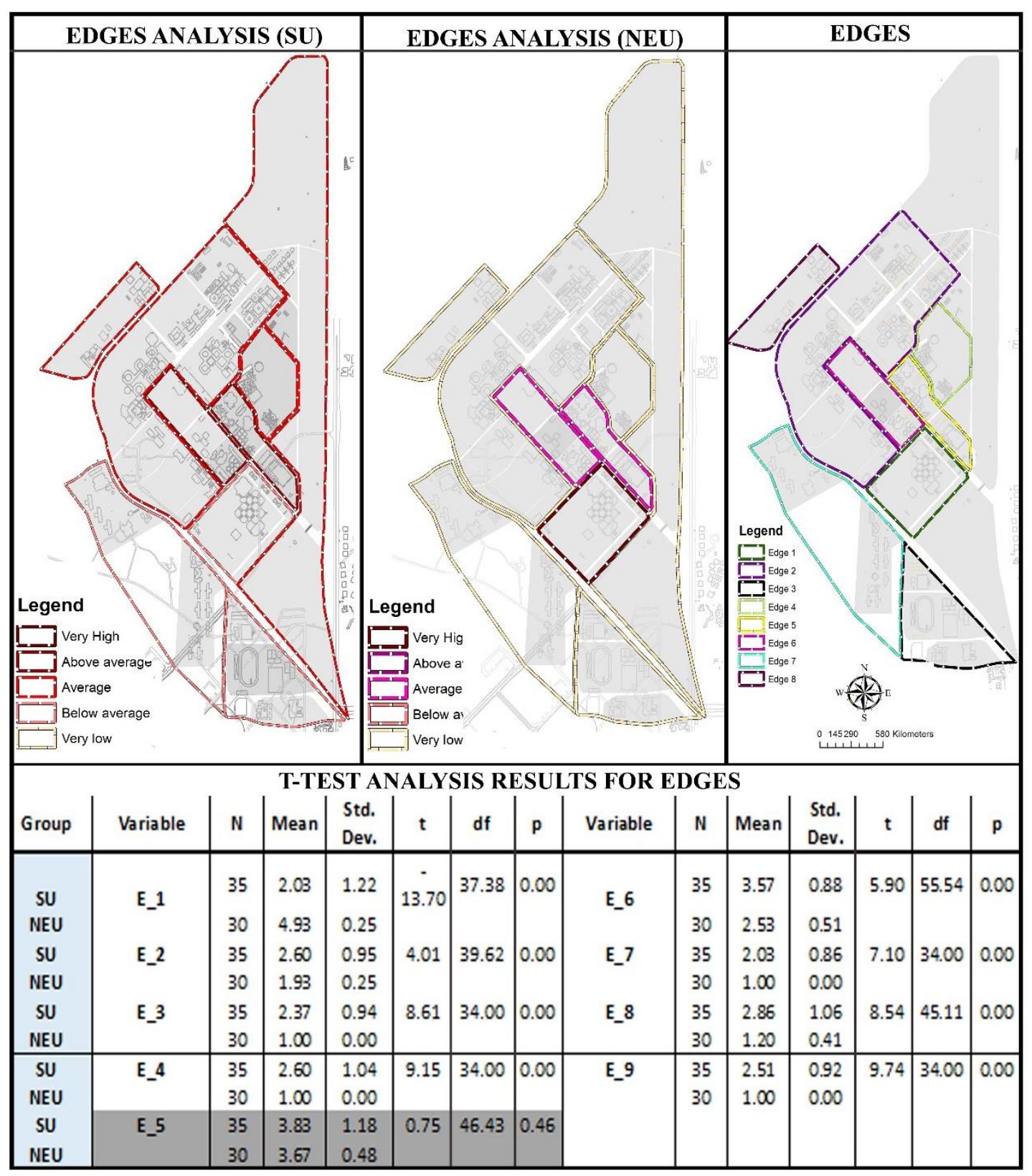

Figure 9. The results of Lynch analysis and T test analysis on edges 
When the map and analysis results on edges were examined, except for the E 5, a statistically significant difference was determined between the averages of these two groups depending on the different variables on $p<0.05$ significance level and in $95 \%$ confidence interval (Figure 9). Edge 5 is an edge which is surrounded by the most used routes by almost all of the students such as cash points, shopping mall and trolley stops. For this reason, Edge 5 is the space which is perceived the most by both of the groups that gave spatial experience (SU) and don't have spatial experience (NEU). For other edges, it was observed that SU students perceived almost all of the edges while navigating in the campus since they knew the campus area. It was determined that apart from the Edge 5, NEU students perceived Edge 1 and Edge 6 where the hospital and the cultural center around it and the administration are located more while navigating.

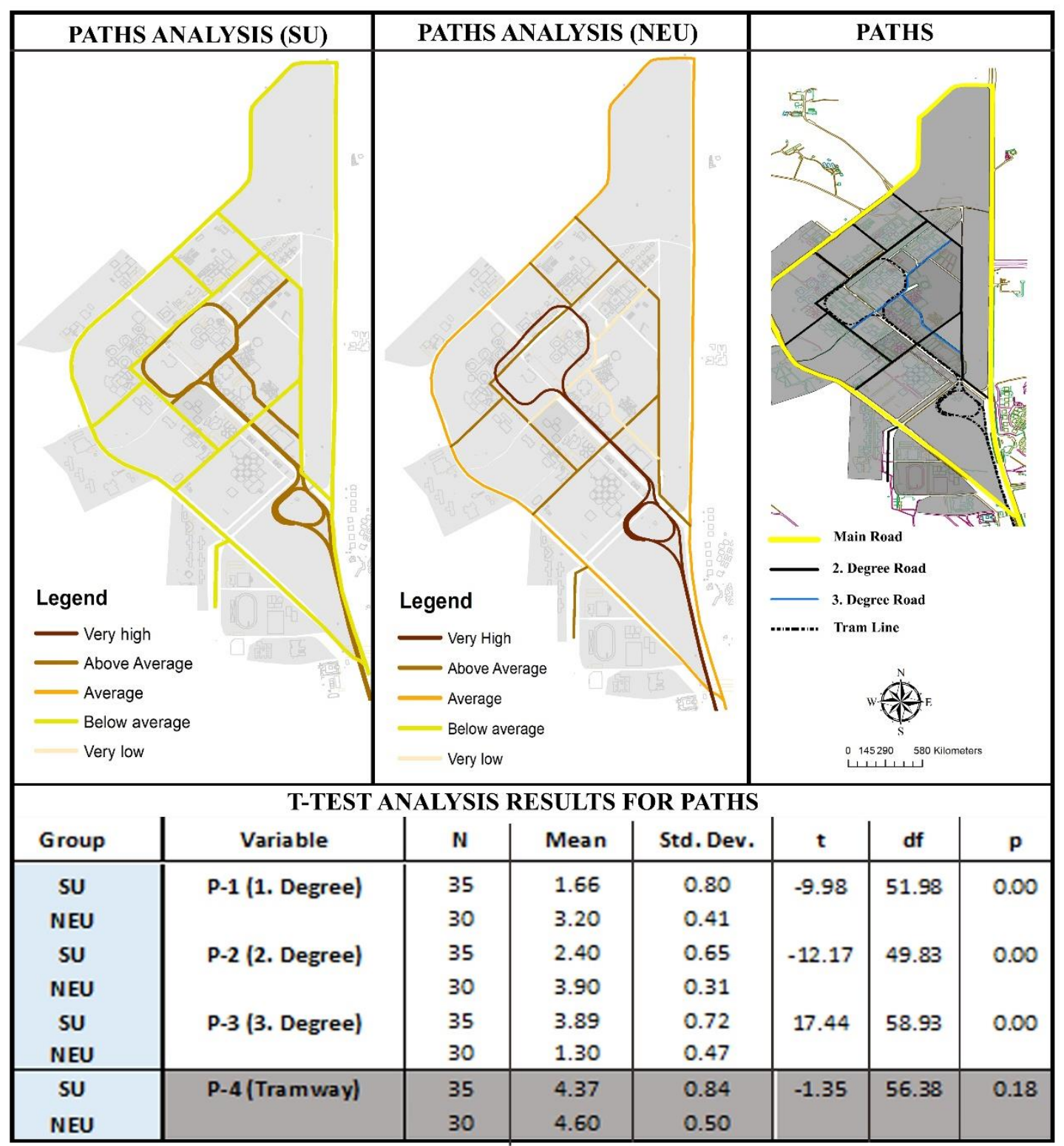

Figure 10. The results of Lynch analysis and $\mathrm{T}$ test analysis on paths 
When the map and analysis results on the paths were examined, except for the trolley route, a statistically significant difference was determined between the averages of these two groups depending on the different variables on $\mathrm{p}<0.05$ significance level and in $95 \%$ confidence interval (Figure 10). The reason why there wasn't a significant difference for the trolley line may derive from the fact that both of the groups use this line more.

\section{DISCUSSION}

Within the scope of the research, the characteristics of the space and the observer were examined which affect the obtaining process of spatial information in 2 and 3 dimensions in the measurement of spatial legibility. According to this, it was determined that there is a significant relationship between the spatial legibility of the campus with the characteristics of the observer and space.

Regarding this, it was determined in the maps which were created in order to determine the effect of the characteristics of the space to the spatial legibility,

- the campus was planned in a geometry which is located in a non-complex and functional clustering that eases the navigation in the $2^{\text {nd }}$ dimension,

- it was located on an accessible topography which does not prevent visibility in $3^{\text {rd }}$ dimension in terms of the slope and

- the landmark structures are visible from certain stops such as trolley stop and focus points. When the analyzes and maps on the characteristics of the spatial characteristics of the campus were examined, the spatial information of the campus in $2^{\text {nd }}$ and in $3^{\text {rd }}$ dimension are easily accessible and can be used fit for purpose. For this reason, the campus is spatially legible.

In the created maps, statistical analyzes and the questionnaire application that was conducted within the scope of lynch analysis (landmarks, districts, nodes, edges and paths) which was carried out in order to determine the effect of the characteristics of the observer (observers who experienced the space and didn't) on the legibility of the space, it was observed that

- the spatial perception levels of students who have spatial experience (SU) were higher on all of the Lynch compounds while navigating and the spatial perception levels of students who didn't have spatial experience (NEU) increase on certain and high-rise structures.

- It was determined that the spatial legibility of the observer increases statistically with the spatial experience.

- It was determined that structures such as faculty of engineering, library and computer centers in which educational activities are carried out, shopping mall district which is used commonly instead of canteen and cafeteria, public structures (such as health services), stops and routes on which there are public transportation vehicles have higher spatial 
legibility for the group that experienced the space (SU) and didn't experience the space (NEU).

When the analyzes and maps on the characteristics of the observer were examined, the group which had spatial experience (SU) can use the spatial information of the campus in $2^{\text {nd }}$ and $3^{\text {rd }}$ dimension fit for purpose by obtaining it more easily than the group which didn't have spatial experience (NEU). For this reason, the legibility of the campus differs in terms of the characteristics of the observer.

In this case, it can be stated that there is a significant relationship between the spatial legibility and the characteristics of the space and the observer.

\section{CONCLUSION}

Planning the whole city or a part of it expresses a process such as producing sustainable spatial policies, planning, creating alternative scenarios and determining the risks. The human factor (expectations, income status, needs, age, education status, gender, etc.) constitute the most important effect for successfully completing this process. For this reason, space and spatial planning independent from humans should not be considered. Planning that is performed on human scale provides the creation of legible spaces by establishing, non-complex, accessible, coherent and distinctive spaces.

For this reason, the spatial legibility of the SU campus which was chosen as the application area within the scope of the research was evaluated by examining it in terms of the characters of the observers which constitute the human factor in addition to its spatial characteristics. It was determined that the spatial characteristics of the campus is perceptible and have open planning in the $2^{\text {nd }}$ and $3^{\text {rd }}$ dimension. It was determined that the characteristics of the observer differ in groups which have and don't have spatial experience and the legibility of the campus also differ according to these groups. Having a lower perception on spatial legibility by the group which doesn't have spatial experience indicate the effect of the observer, in other words, the human factor on spatial planning. According to this, the human factor has a significant relationship with the planning process.

This research indicates that spaces in the planning process could be legible by

- being easily accessible and fit for purpose in terms of the functionality, slope and visibility of the spatial information which would be created in $2^{\text {nd }}$ and $3^{\text {rd }}$ dimension and

- being perceptible for observers (living people and visitors) and in accordance with their characteristics. 


\section{KAYNAKLAR}

[1] F.C. Bilsel, S.G. Bilsel, A.A. Bilsel, Kuramsal yaklaşımlardan kentsel mekan tasarımına, 1. Ulusal Kentsel Tasarım Kongresi, (1999).

[2] G. Bell, P. Dourish, Getting out of the city: Meaning and structure in everyday encounters with space. In Workshop on Ubiquitous Computing on the Urban Frontier, Ubicomp. (2004).

[3] S. Kaplan, R. Kaplan, The visual environment: Public participation in design and planning. Journal of Social Issues, 45(1), (1989), 59-86.

[4] A. E. Stamps, Mystery, complexity, legibility and coherence: A meta-analysis. Journal of environmental psychology, 24(1), (2004), 1-16.

[5] E. Köseoğlu, D. E. Önder, Mekânsal Okunabilirlik Kavramının Çözümlenmesi. Yapı Dergisi, 343, (2010), 52-56.

[6] O. Belir, D.E. Önder, Accessibility in Public Spaces: Spatial legibility for visually impaired people. In Proceedings of the Ninth International Space Syntax Symposium Edited by Kim, YO, Park, HT and Seo, KW, (2013).

[7] R. Passini, Wayfinding in architecture. (Environmental Design Series, New York: Van Nostrand Reinhold, 1984).

[8] K. Lynch, The image of the city, (ma: mit press, Cambridge, 1960).

[9] D. Appleyard, Why buildings are known: A predictive tool for architects and planners. Environment and Behavior, 1(2), (1969), 131-156.

[10] J. Weisman, Evaluating architectural legibility: Way-finding in the built environment. Environment and Behavior, 13(2), (1981),189-204.

[11] T. Gärling, A. Böök, E. Lindberg, Spatial orientation and wayfinding in the designed environment: A conceptual analysis and some suggestions for postoccupancy evaluation. Journal of architectural and planning research, (1986), 55-64.

[12] E. Köseoğlu, D.E. Önder, Subjective and objective dimensions of spatial legibility. Procedia-Social and Behavioral Sciences, 30, (2011), 1191-1195.

[13] N. Dehghan, A.M. Moradi, G.H. Memariyan, Comparing the Dimensions of Spatial Legibility with Wayfinding Strategies. International Research Journal of Applied and Basic Sciences, 3, (2012), 2637-2646.

[14] E. Kürkçüoğlu, M. Ocakçı, Kentsel Dokuda Mekânsal Yönelme Üzerine Bir Algı-Davranış Çalışması: Kadıköy Çarşı Bölgesi. Megaron, 10(3), (2015), 365-388.

[15] B. Güç, Okunabilirlik Ve Erişilebilirlik Açısından Hastane Dolaşım Alanlarındaki Mekânsal Düzenin Etkisi: Süleyman Demirel Üniversitesi Poliklinikleri. Mühendislik Bilimleri ve Tasarım Dergisi, 3(3), (2015), 425-432.

[16] K. D. Topçu, M. Topçu, Visual presentation of mental images in urban design education: cognitive maps. Procedia-Social and Behavioral Sciences, 51, (2012), 573-582.

[17] Y. A. Türk, B. Sen, A. Özyavuz, Students exploration on campus legibility. Procedia-Social and Behavioral Sciences, 197, (2015), 339-347. 
[18] S. Suthasupa, The Portrayal of a City's Image by Young People. Procedia-Social and Behavioral Sciences, 38, (2012), 284-292.

[19] I. Delikostidis, J. Engel, B. Retsios, C.P. Van Elzakker, M. J. Kraak, J. Döllner, Increasing the usability of pedestrian navigation interfaces by means of landmark visibility analysis. The Journal of Navigation, 66(4), (2013), 523-537.

[20] N. Taylor, Legibility and aesthetics in urban design. Journal of Urban design, 14(2), (2009), 189202.

[21] T. R., Herzog, O.L. Leverich, Searching for legibility. Environment and Behavior, 35(4), (2003), 459-477.

[22] H. Safari, F.F. Moridani, S.S. Mahdzar, Influence of geometry on legibility: An explanatory design study of visitors at the Kuala Lumpur City Center. Frontiers of Architectural Research, 5(4), (2016), 499-507.

[23] D.M., Kelly, W.F. Bischof, Orienting in virtual environments: How are surface features and environmental geometry weighted in an orientation task?. Cognition, 109(1), (2008), 89-104.

[24] A. P. N. De Faria, R. Krafta, Representing urban cognitive structure through spatial differentiation, In 4th International Space Syntax Symposium, (2003).

[25] A. Baskaya, C. Wilson, Y.Z. Özcan, Wayfinding in an unfamiliar environment: Different spatial settings of two polyclinics, Environment and Behavior, 36(6), (2004), 839-867.

[26] Z. Eraydin, Building a Legible City: How Far Planning is Successful in Ankara (Doctoral dissertation, Middle East Technical University), (2007).

[27] T. Ishikawa, D. R. Montello, Spatial knowledge acquisition from direct experience in the environment: Individual differences in the development of metric knowledge and the integration of separately learned places. Cognitive psychology, 52(2), (2006), 93-129.

[28] R. Dalton, S. Bafna, The syntactical image of the city: A reciprocal definition of spatial elements and spatial syntaxes. 4th International Space Syntax Symposium (2003).

[29] A. Rapoport, Human Aspects of Urban Form: Towards a Man - Environment Approach to Urban Form and Design, (Pergamon Press, UK, 1977).

[30] G. Cullen, The Concise Townscape. (Architectural Press,London, UK: Paisagem Urbana,1961).

[31] R. Chang, T. Butkiewicz, C. Ziemkiewicz, Z. Wartell, N. Pollard, W. Ribarsky, Legible simplification of textured urban models. IEEE Computer Graphics and Applications, 28(3), (2008), $27-36$.

[32] F. Habib, M. Sashourpour, The Cognition of the City at Night. International Journal of Architecture and Urban Development, 2(3), (2012), 5-12.

[33] Ç. Kol, S. Küpçü, ArcGIS Spatial Analyse. Ankara, TR:İşlem Coğrafi Bilgi Sistemleri Mühendisliği ve Eğitim Ltd. Şti Yayınları, (2008).

[34] P. Bartie, S. Mills, S. Kingham, An egocentric urban viewshed: A method for landmark visibility mapping for pedestrian location based services. In Geospatial Vision: new dimensions in cartography, 4, (2008), 61-85. 
[35] W. Michelson, An empirical analysis of urban environmental perception. Journal of American Institute of Planners, 32, (1966), 355-360.

[36] D. Pocock, R. Hudson, Environmental cognition in cross-cultural perspective. Environmental Knowing. Stroudsburg, PA: Dowden, Hutchinson and Ross. London, UK: Macmillan, (1978).

[37] M. J. Proulx, O. S. Todorov, A. Taylor Aiken, A.A. de Sousa, Where am I? Who am I? The relation between spatial cognition, social cognition and individual differences in the built environment. Frontiers in psychology, 7(64), (2016), 1-23. 